\title{
SCIDOC
}

\author{
International Journal of Dentistry and Oral Science (IJDOS) \\ ISSN: 2377-8075
}

\section{Knowledge, Awareness And Practice Of Bioceramics Materials Among Dental Practitioners And Specialists}

Research Article

Indumathi $\mathrm{M}^{1}$, Dr. Mahalakshmi $\mathrm{J}^{2 *}$

${ }^{1}$ Undergraduate Student, Saveetha Dental College and Hospitals, Saveetha Institute of Medical and Technical Sciences (SIMATS), Saveetha University, Chennai- 77, India.

${ }^{2}$ Senior Lecturer, Department of Conservative Dentistry and Endodontics, Saveetha Dental College and Hospitals, Saveetha Institute of Medical and Technical Sciences [SIMATS], Saveetha University, Chennai- 77, India.

\section{Abstract}

Introduction: Over the past five years, new technologies have been developed that permits dentists to perform wonderful endodontics procedures. The reason for these changes is the introduction of bioceramic materials. The beauty is that endodontic material science is continuing to improve and it has been changed. The increased use of bioceramic technology in endodontics has been raised nowadays, more specifically in the area of endodontic obscuration. Bioceramics are materials which include ceramic materials which are used in medicine and dentistry. The examples of bioceramics materials are biodentine, mineral trioxide aggregate, lumina, zirconia.

Aim: The aim of the present study was to assess the knowledge, awareness and practice of bio ceramics materials among dental practitioners and specialists.

Materials and Methods: Self-administered questionnaire was prepared and it was distributed among dental practitioners and specialists through the online survey "google forms". SPSS software was used to analyse the results. Chi square test was used as inferential statistics.

Results: About $74.7 \%$ of the participants were aware that bio ceramics materials possess antibacterial properties and $80.7 \%$ of the participants were aware that bio ceramics can be used as a pulp capping agent. Regarding the use of bio ceramic materials in dentistry , $13.2 \%$ of the participants answered to filling up bony defects, $12.2 \%$ of the participants answered to root repair materials, $17.5 \%$ of the participants answered to retrograde filling materials, $17.7 \%$ of the participants answered to aids in retrograde filling materials nd $56.1 \%$ of the participants answered to all the above.

Conclusion: The overall knowledge, awareness and practice on bio ceramic material tends to be moderate among the dental practitioners and specialists.

Keywords: Antibacterial; Bioceramics; Innovative Material; Mineral Trioxide Aggregate;Technologies.

\section{Introduction}

Over the past five years, new technologies have been developed that permits dentists to perform successful endodontics procedures. The reason for these changes is the introduction of bioceramic materials. The beauty is that endodontic material science is continuing to improve and has yielded better results. The increased use of bioceramic technology in endodontics have been raised nowadays, more specifically in the area of endodontic obturation [1]. Bioceramics are materials which include ceramic ma- terials which are used in medicine and dentistry. The examples of bioceramics materials are biodentine, mineral trioxide aggregate, lumina, zirconia, bioactive glass, glass ceramics, hydroxyapatite and resorbable calcium phosphates. In dentistry, bioceramics are used in dental implants, in periodontal treatment, alveolar ridge augmentation, maxillofacial surgery, pulp capping and open apes management [2]. Bioceramics are used in dentistry for various purposes like root repair materials, apical fill materials, bio ceramic sealers and endodontic sealers. Bio ceramics have advantages like biocompatibility, non-toxicity, dimensional stability $[3,4]$.

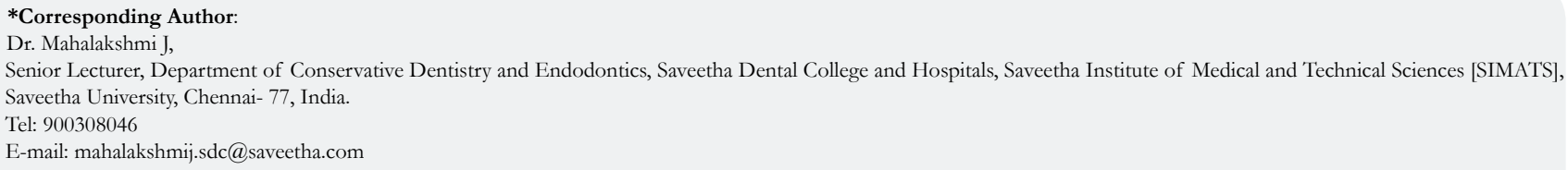

Citation: Indumathi M, Dr. Mahalakshmi J. Knowledge, Awareness And Practice Of Bioceramics Materials Among Dental Practitioners And Specialists. Int J Dentistry Oral Sci. 2021;8(9):4683-4688. doi: http://dx.doi.org/10.19070/2377-8075-21000953

Copyright: Dr. Mahalakshmi J ${ }^{\circ}$ 2021. This is an open-access article distributed under the terms of the Creative Commons Attribution License, which permits unrestricted use, distribution and reproduction in any medium, provided the original author and source are credited. 
Bioceramics can be classified as Bioinert, bioactive and biodegradable, or soluble or resorbable There are numerous bioceramics currently in use in both dentistry and medicine [4]. Bioceramics have wonderfully biocompatibility and nontoxic properties due to their similarity with biological hydroxyapatite. They also possess intrinsic osteoinductive property because of their excellent ability to absorb osteoinductive substances if there is a bone healing process happening nearby. Bioceramic materials also possess the ability to achieve excellent hermetic seal and also have good radiopacity . Bioceramic materials also possess antibacterial properties [5]. There advantages of using bioceramic materials as root canal sealers is their biocompatibility prevents rejection by the surrounding tissues and bioceramic materials contain calcium phosphate which enhances the setting properties of bioceramics and results in a crystalline structure similar to tooth thereby improving sealer-to-root dentin bonding [6]. Bioceramic material plays an important role in the pulp capping and pulpotomy procedures. For all these reasons, bioceramic materials are now the material of choice for pulp capping, pulpotomy, perforation repair, root-end filling, as well as for sealing root canal fillings [7]. It is interesting to note that new generation bioceramic materials have demonstrated the ability to overcome some of the important imitations of earlier generations bioceramic endodontic materials. Most bioceramic materials have been shown to be biocompatible therefore having a potential use in clinical endodontics [8].

Our team has extensive knowledge and research experience that has translated into high quality publications [9-28]. The aim of the present study was to assess the knowledge, awareness and practice of bio ceramics materials among dental practitioners and specialists.

\section{Materials and Methods}

\section{Study design:}

A cross sectional study was conducted through an online survey from February to March 2021 among dental practitioners and specialist.

\section{Study subjects:}

A simple random sampling was used to select the study participants.

\section{Inclusion criteria:}

All the dental practitioners and specialists who were willing to participate were included.

\section{Ethical considerations:}

Returning the filled questionnaire was considered as implicit consent as a part of the survey. Ethical approval for the study was obtained from the Institutional Review Board (IRB), Saveetha Dental College.

\section{Study methods:}

Self-administered questionnaire of close ended questions was prepared and it was distributed among dental practitioners and specialists from February to April 2021 through the online survey "google forms". The collected data were checked regularly for clarity, competence, consistency, accuracy and validity. Demographic details were also included in the questionnaire.

\section{Statistical analysis:}

Data was analysed with SPSS version (22.0). Descriptive statistics as percent were calculated to summarise qualitative data. Chi square test was used to analyze and the confidence level was 95\% and of statistical significance $\mathrm{P}<0.05$. Finally, the result was presented by using bar charts, pie charts and percentage tables.

\section{Results}

Among 150 participants, 46.4\% were males and 53.6\% were females. Regarding the year of experience, $33.3 \%$ had $0-5$ years of experience, $33.3 \%$ had 5-10 years of experience and $33.3 \%$ had above 10 years of experience. In the present study, 33.3\% of the participants belong to general practitioners, $33.3 \%$ of the participants belong to endodontists and $33.3 \%$ of the participants belong to post graduates. About $77.5 \%$ of the participants were aware that bio ceramics materials are used in endodontics. In the present study $79.3 \%$ of the participants were aware that bio ceramics materials are biocompatible and non-toxic. About $62 \%$ of the participants were aware that bio ceramics can be used as a pulp capping agent(Figure 1) and $75.7 \%$ of the participants were aware that bio ceramics materials possess antibacterial properties(Figure 2) . Regarding the use of bio ceramic materials in dentistry , $13.3 \%$ of the participants answered to filling up bony defects, $12.3 \%$ of the participants answered to root repair materials, $17.7 \%$ of the participants answered to retrograde filling materials while $56.7 \%$ of the participants answered to all the above. About $59.6 \%$ of the participants responded to Mineral trioxide aggregate, $40.3 \%$ of the participants responded to biodentine as the first bio ceramics material introduced to clinical use (Figure 3). About $46.7 \%$ of the participants responded to mineral trioxide aggregate, $24.3 \%$ of the participants responded to Portland cement, $29 \%$ of the participants responded to calcium silicate cement as bio ceramics material which is used to promote greater osteoblastic differentiation. To the question why MTA is better than Portland cement, $13.3 \%$ of the participants responded due to its smaller particle, $12.3 \%$ of the participants responded due to its bio activity, $17.7 \%$ of the participants responded due to its bio mineralization. Regarding the kind of bio ceramics they prefer to use in dentistry, $40.7 \%$ of the participants responded to Bio inert, $42 \%$ of the participants responded to Bio active, $17.3 \%$ of the participants responded to Biodegradable. About $31.7 \%$ of the participants prefer bio ceramics in dentistry due its excellent biocompatibility, $17.7 \%$ of the participants responded to excellent hermetic seals, and $48.7 \%$ of the participants responded to all the above. About $77.5 \%$ of the participants used bio ceramics material in their practice. Regarding the purpose of using bio ceramics materials, $23.3 \%$ of the participants responded to as an open apex management, $35.7 \%$ of the participants responded to perforation repair and $41 \%$ of the participants responded to all the above(Figure 4). Regarding the reason for not using bio ceramics, $12.3 \%$ of the participants responded to not being aware of thus usage , $13.3 \%$ of the participants responded to high cost, $17.7 \%$ of the participants responded to difficulty to handle, $56.7 \%$ of 
Figure 1. Pie chart representing awareness on bioceramics materials as pulp capping agents. Blue colour represents yes and green colour represent no. $62 \%$ were aware of it.

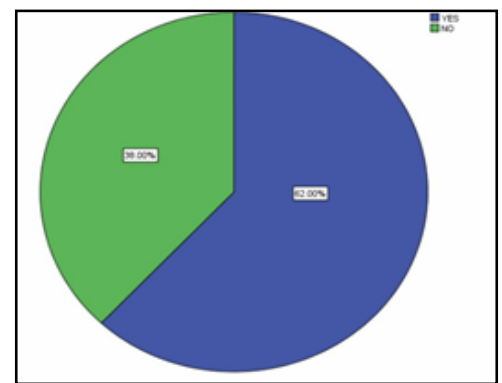

Figure 2. Pie chart representing awareness on bioceramics possess antibacterial properties. Blue colour represents yes and green colour represent. $75.6 \%$ were aware of it.

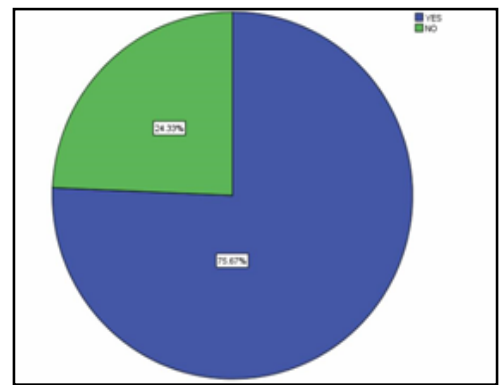

Figure 3. Pie chart representing knowledge on what was the first bioceramics material introduced to clinical use. Blue colour represents MTA and green colour represent Biodnetine.59.6\% had good knowledge.

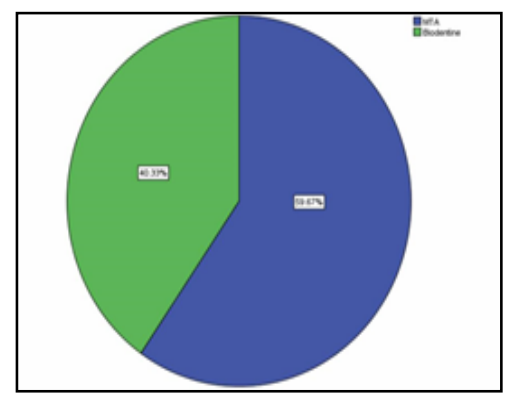

Figure 4. Pie chart representing purpose of using bioceramics material. Blue colour represents open apex management, green colour represents perforation repair and sandal colour represents all the above. $41 \%$ responded to all the above.

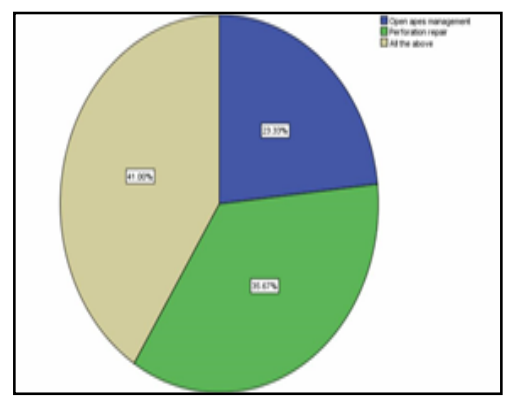

the participants responded to better success rate with other materials.

\section{Discussion}

About $62 \%$ were aware that bioceramics materials can be used as pulp capping agents. 42 participants of endodontists, 45 participants of dental practitioners and 44 participants of post graduates were well aware of it. Majority of post graduates were well aware that bioceramics materials can be used as pulp capping agents. There was a significant difference between the specialist and awareness level. Pearson chi square test- 81.834, $\mathrm{P}$ value $=$
$0.000(<0.05)$ - statistically significant(Figure 5). In the previous study conducted by Liu et al, human dental pulp cells differentiate very well even in the place contacted with MTA or iRoot BP plus in vitro. MTA and iRoot BP Plus both enhanced the proliferation of human dental pulp cells which was statistically significant with $\mathrm{P}<.05$. MTA exhibited good biocompatibility to pulp tissue and induced the proliferation of dental pulp cells and the formation of reparative dentin bridges. Bioceramic materials can be used as a pulp capping material for vital pulp therapy [29].

About $75.6 \%$ were aware that bioceramics possess antibacterial properties. 45 participants of endodontists, 41 participants of dental practitioners and 42 participants of post graduates were 
well aware that bioceramics materials possess antibacterial properties. Majority of endodontists were well aware that bioceramics materials possess antibacterial properties. There was a significant difference between the specialist and awareness level. Pearson chi square test- $80.526, \mathrm{P}$ value $=0.000(<0.05)$ - statistically significant(Figure 6 ). In the previous study conducted by Elshamy et al, bioceramics demonstrated antibacterial property against both staphylococcus aureus and E.coli strains by destroying their outer cell membrane integrity and virulence factor. Thus bioceramic materials also possess antibacterial properties and help in prevention of dental diseases [5].

About $46.7 \%$ responded to MTA, 29\% responded to calcium silicate cement and $24.4 \%$ responded to Portland cement as the bioceramics material used to promote osteoblast differentiation. 36 participants of endodontists, 36 participants of dental practitioners and 32 participants of post graduates responded to Mineral trioxide aggregate(MTA). Majority of endodontists had good knowledge. There was a significant difference between the specialist and knowledge level. Pearson chi square test-177.040, $\mathrm{P}$ value $=0.000(<0.05)$ - statistically significant. endodontists had good knowledge because of different curriculum patterns and levels of knowledge increase with increasing levels of education. In the previous study, The important component of MTA bioceramic is calcium phosphate ceramic which has induced bone formation. The material-dependent property of calcium phosphate-induced osteogenesis suggests strongly the possibility to develop calcium phosphate-based biomaterials with intrinsic osteoinductive property [30].

About $59.6 \%$ of the participants responded to the correct answer accurately as MTA and $40.3 \%$ of the participants responded to biodentine. 45 participants of endodontists, 41 participants of dental practitioners and 42 participants of post graduates responded to Mineral trioxide aggregate(MTA) as the first bioceramics material introduced to clinical use. Majority of endodontists followed by dental practitioners had good knowledge when compared to postgraduates. There was a significant difference between the specialist and knowledge on what was the first bioceramics material introduced to clinical use. Pearson chi square test- 96.182 , P value $=0.000(<0.05)-$ statistically significant(Figure 7$)$. The first bioceramic material successfully used in endodontics was the MTA cement which was introduced by Dr.Torabinejad in 1993. It is osteoconductive, inductive and biocompatible. This material was

Figure 5. Bar graph representing the association of specialist and awareness on bioceramics materials as pulp capping agent. $\mathrm{X}$ axis represents the specialist and $\mathrm{Y}$ axis represents the number of participants responded, blue colour denotes yes and green colour denotes no. Majority of endodontists were well aware that bioceramics materials can be used as pulp capping agents. There was a significant difference between the specialist and awareness level. Pearson chi square test- 81.834, $P$ value $=0.000(<0.05)$ - statistically significant .

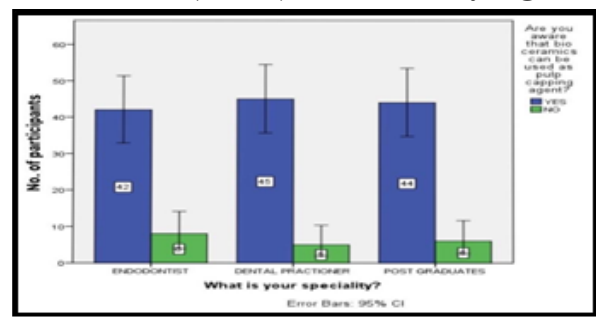

Figure 6. Bar graph representing the association of specialists and awareness on bioceramics possess antibacterial properties. $\mathrm{X}$ axis represents the specialist and $\mathrm{Y}$ axis represents the number of participants responded, blue colour denotes yes and green colour denotes no. Majority of endodontists were well aware that bioceramics materials possess antibacterial properties. There was a significant difference between the specialist and awareness level. Pearson chi square test- 80.526, $P$ value $=0.000(<0.05)-$ statistically significant

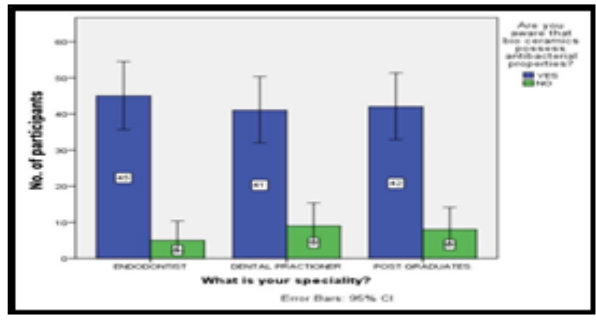

Figure 7. Bar graph representing the association of specialist and knowledge on what was the first bioceramics material introduced to clinical use. $\mathrm{X}$ axis represents the specialist and $\mathrm{Y}$ axis represents the number of participants responded, blue colour denotes MTA, green colour denotes biodentine. Majority of endodontists followed by dental practitioners had good knowledge. There was a significant difference between the specialist and knowledge level. Pearson chi square test- 96.182 ,

$P$ value $=0.000(<0.05)$ - statistically significant

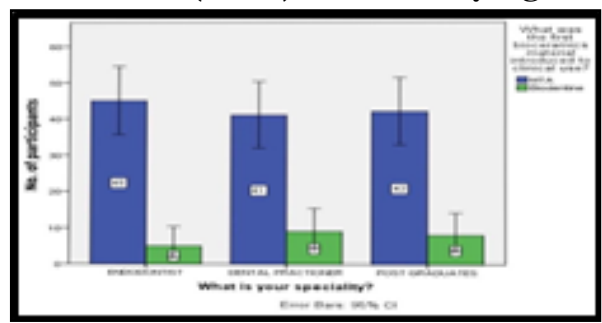


Figure 8. Bar graph representing the association of specialist and purpose of using bioceramics material. $\mathrm{X}$ axis represents the specialist and $\mathrm{Y}$ axis represents the number of participants responded, blue colour denotes all the above, sandal colour denotes perforations repair and green colour denotes open apes management . Majority of endodontists responded to all the above. There was a significant difference between the specialist and purpose of using bioceramics material. Pearson chi square test-171.280, $P$ value $=0.000(<0.05)$ - statistically significant

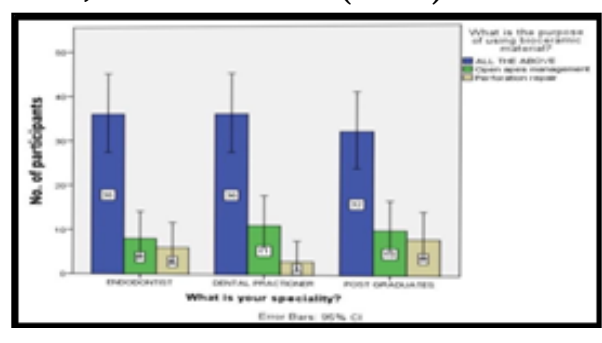

developed and recommended initially as a root-end filling material and subsequently has been used for pulp capping, pulpotomy, apical barrier formation in teeth with open apexes, repair of root perforations, and as a root canal filling material [31].

Regarding the purpose of using bioceramics material, about $41 \%$ of the participants responded to all the above, $35.7 \%$ of the participants responded to the perforation repair and $23.3 \%$ of the participants responded to the open apes management. 36 participants of endodontists, 36 participants of dental practitioners and 32 participants of post graduates responded to all the above. Majority of endodontists responded to all the above. There was a significant difference between the specialist and purpose of using bioceramics material. Pearson chi square test-171.280, $\mathrm{P}$ value $=0.000(<0.05)-$ statistically significant $($ Figure 8$)$. Bioceramic materials, with their biocompatible nature, non toxic and excellent physicochemical properties, are widely used in endodontic applications. They can function as cements, root repair materials, perforation materials, root canal sealers and filling materials, which have the advantages of enhanced biocompatibility [32].

Regarding the preference of bioceramics material in dentistry. About $48.7 \%$ of the participants responded to the all the above, $31.7 \%$ of the participants responded to the excellent biocompatibility and $19.7 \%$ of the participants responded to the excellent hermetic seal. Bioceramics are produced in a variety of forms and phases and provide many different functions in repair of the human body. In dentistry, bioceramics are used in the form of bulk or porous materials with a specific shape such as implant, prostheses, or prosthetic devices due to their excellent biocompatibility, excellent hermetic seal [33].

The present study is a novel study, hence there is no existing previous studies. The reason for the better knowledge, awareness and practice among endodontists is that they follow different curriculum patterns including CAD/CAM technologies and they are well exposed to clinical cases. Limitation of the study is less sample size. In future an extensive study with large sample size and varied population can be used to assess the awareness, knowledge and practice on bioceramics materials among dental practitioners and specialists.

\section{Conclusion}

The overall awareness, knowledge and practice on bioceramics materials tends to be moderate among dental practitioners and specialists . From the present survey, endodontists have a good knowledge, awareness and practice when compared dental practitioners and post graduates. Being dentists the utility of the bioceramic materials should be incorporated into the curriculum for its better application.

\section{Acknowledgement}

This research was done under the supervision of the Department of Research of Saveetha Dental College and Hospitals. We sincerely show gratitude to the corresponding guides who provided insight and expertise that greatly assisted the research.

\section{Funding}

- Saveetha Dental College and Hospitals

- Saveetha Institute of Medical and Technical Sciences

- $\quad$ RVR Engineering

\section{References}

[1]. Jain P, editor. Current therapy in endodontics. John Wiley \& Sons; 2016 Oct 17:336.

[2]. Drukteinis S, Camilleri J, editors. Bioceramic Materials in Clinical Endodontics. Springer International Publishing; 2021.

[3]. Torres FFE, Pinto JC, Figueira GO, Guerreiro-Tanomaru JM, TanomaruFilho M. A micro-computed tomographic study using a novel test model to assess the filling ability and volumetric changes of bioceramic root repair materials. Restor Dent Endod. 2020 Dec 8;46(1):e2.Pubmed PMID: 33680891.

[4]. Abdelmotelb MA, Gomaa YF, Khattab NMA, Elheeny AAH. Premixed bioceramics versus mineral trioxide aggregate in furcal perforation repair of primary molars: in vitro and in vivo study. Clin Oral Investig. 2021 Aug;25(8):4915-4925.Pubmed PMID: 33483869.

[5]. Elshamy FM, Singh G, Elraih H, Gupta I, Idris FA. Antibacterial Effect of New Bioceramic Pulp Capping Material on the Main Cariogenic Bacteria. J Contemp Dent Pract. 2016 May 1;17(5):349-53.Pubmed PMID: 27443359.

[6]. Jitaru S, Hodisan I, Timis L, Lucian A, Bud M. The use of bioceramics in endodontics-literature review. Clujul Med. 2016;89(4):470-3.

[7]. Abusrewil SM, McLean W, Scott JA. The use of Bioceramics as root-end filling materials in periradicular surgery: A literature review. Saudi Dent J. 2018 Oct;30(4):273-282.Pubmed PMID: 30202163.

[8]. Kokubo T, editor. Bioceramics and their clinical applications. Elsevier; 2008 Mar 25:784.

[9]. Muthukrishnan L. Imminent antimicrobial bioink deploying cellulose, alginate, EPS and synthetic polymers for 3D bioprinting of tissue constructs. Carbohydr Polym. 2021 May 15;260:117774.Pubmed PMID: 33712131.

[10]. PradeepKumar AR, Shemesh H, Nivedhitha MS, Hashir MMJ, Arockiam S, Uma Maheswari TN, et al. Diagnosis of Vertical Root Fractures by Conebeam Computed Tomography in Root-filled Teeth with Confirmation by Direct Visualization: A Systematic Review and Meta-Analysis. J Endod. 2021 Aug;47(8):1198-1214.Pubmed PMID: 33984375.

[11]. Chakraborty T, Jamal RF, Battineni G, Teja KV, Marto CM, Spagnuolo 
G. A Review of Prolonged Post-COVID-19 Symptoms and Their Implications on Dental Management. Int J Environ Res Public Health. 2021 May 12;18(10):5131.Pubmed PMID: 34066174

[12]. Muthukrishnan L. Nanotechnology for cleaner leather production: a review. Environ Chem Lett. 2021 Jan 13;19(3):2527-49.

[13]. Teja KV, Ramesh S. Is a filled lateral canal - A sign of superiority? J Dent Sci. 2020 Dec;15(4):562-563.Pubmed PMID: 33505634.

[14]. Narendran K, MS N, SARVANAN A, SUKUMAR E. Synthesis, Characterization, Free Radical Scavenging and Cytotoxic Activities of Phenylvilangin, a Substituted Dimer of Embelin. Indian J. Pharm. Sci. 2020 Sep 1;82(5).

[15]. Reddy P, Krithikadatta J, Srinivasan V, Raghu S, Velumurugan N. Dental Caries Profile and Associated Risk Factors Among Adolescent School Children in an Urban South-Indian City. Oral Health Prev Dent. 2020 Apr 1;18(1):379-386.Pubmed PMID: 32618460.

[16]. Sawant K, Pawar AM, Banga KS, Machado R, Karobari MI, Marya A, et al. Dentinal Microcracks after Root Canal Instrumentation Using Instruments Manufactured with Different NiTi Alloys and the SAF System: A Systematic Review. Appl Sci. 2021 Jan;11(11):4984.

[17]. Bhavikatti SK, Karobari MI, Zainuddin SLA, Marya A, Nadaf SJ, Sawant VJ, et al. Investigating the Antioxidant and Cytocompatibility of Mimusops elengi Linn Extract over Human Gingival Fibroblast Cells. Int J Environ Res Public Health. 2021 Jul 4;18(13):7162.Pubmed PMID: 34281099.

[18]. Karobari MI, Basheer SN, Sayed FR, Shaikh S, Agwan MAS, Marya A, et al. An In Vitro Stereomicroscopic Evaluation of Bioactivity between Neo MTA Plus, Pro Root MTA, BIODENTINE \& Glass Ionomer Cement Using Dye Penetration Method. Materials (Basel). 2021 Jun 8;14(12):3159.Pubmed PMID: 34201321

[19]. Rohit Singh T, Ezhilarasan D. Ethanolic extract of Lagerstroemia Speciosa (L.) Pers., induces apoptosis and cell cycle arrest in HepG2 cells. Nutr Cancer. 2020 Jan 2;72(1):146-56.

[20]. Ezhilarasan D. MicroRNA interplay between hepatic stellate cell quiescence and activation. Eur J Pharmacol. 2020 Oct 15;885:173507.Pubmed PMID: 32858048 .

[21]. Romera A, Peredpaya S, Shparyk Y, Bondarenko I, Bariani GM, Abdalla $\mathrm{KC}$, et al. Bevacizumab biosimilar BEVZ92 versus reference bevacizumab in combination with FOLFOX or FOLFIRI as first-line treatment for metastatic colorectal cancer: a multicentre, open-label, randomised controlled trial. Lancet Gastroenterol Hepatol. 2018 Dec 1;3(12):845-55.

[22]. Raj R K, D E, S R. 囚-Sitosterol-assisted silver nanoparticles activates Nrf2 and triggers mitochondrial apoptosis via oxidative stress in human hepatocellular cancer cell line. J Biomed Mater Res A. 2020 Sep;108(9):18991908.Pubmed PMID: 32319188.
[23]. Vijayashree Priyadharsini J. In silico validation of the non-antibiotic drugs acetaminophen and ibuprofen as antibacterial agents against red complex pathogens. J Periodontol. 2019 Dec;90(12):1441-1448.Pubmed PMID: 31257588.

[24]. Priyadharsini JV, Girija AS, Paramasivam A. In silico analysis of virulence genes in an emerging dental pathogen A. baumannii and related species. Arch. Oral Biol. 2018 Oct 1;94:93-8.

[25]. Uma Maheswari TN, Nivedhitha MS, Ramani P. Expression profile of salivary micro RNA-21 and 31 in oral potentially malignant disorders. Braz Oral Res. 2020 Feb 10;34:e002.Pubmed PMID: 32049107.

[26]. Gudipaneni RK, Alam MK, Patil SR, Karobari MI. Measurement of the Maximum Occlusal Bite Force and its Relation to the Caries Spectrum of First Permanent Molars in Early Permanent Dentition. J Clin Pediatr Dent. 2020 Dec 1;44(6):423-428.Pubmed PMID: 33378468.

[27]. Chaturvedula BB, Muthukrishnan A, Bhuvaraghan A, Sandler J, Thiruvenkatachari B. Dens invaginatus: a review and orthodontic implications. $\mathrm{Br}$ Dent J. 2021 Mar;230(6):345-350.Pubmed PMID: 33772187.

[28]. Kanniah P, Radhamani J, Chelliah P, Muthusamy N, Joshua Jebasingh Sathiya Balasingh Thangapandi E, Reeta Thangapandi J, et al. Green synthesis of multifaceted silver nanoparticles using the flower extract of Aerva lanata and evaluation of its biological and environmental applications. ChemistrySelect. 2020 Feb 21;5(7):2322-31.

[29]. Liu S, Wang S, Dong Y. Evaluation of a bioceramic as a pulp capping agent in vitro and in vivo. J Endod. 2015 May 1;41(5):652-7.

[30]. Wu L, Zhou C, Zhang B, Lei H, Wang W, Pu X, et al. Construction of Biomimetic Natural Wood Hierarchical Porous-Structure Bioceramic with Micro/Nanowhisker Coating to Modulate Cellular Behavior and Osteoinductive Activity. ACS Appl Mater Interfaces. 2020 Oct 28;12(43):4839548407.Pubmed PMID: 33064436.

[31]. Coaguila-Llerena H, Ochoa-Rodriguez VM, Castro-Núñez GM, Faria G, Guerreiro-Tanomaru JM, Tanomaru-Filho M. Physicochemical Properties of a Bioceramic Repair Material - BioMTA. Braz Dent J. 2020 Sep;31(5):511-5.

[32]. Poli E, Magnaudeix A, Damia C, Lalloué F, Chaleix V, Champion E, et al. Advanced protocol to functionalize $\mathrm{CaP}$ bioceramic surface with peptide sequences and effect on murine pre-osteoblast cells proliferation. Bioorg Med Chem Lett. 2019 May 1;29(9):1069-1073.Pubmed PMID: 30852082.

[33]. de Oliveira Junior JM, Montagner PG, Carrijo RC, Martinez EF. Physical characterization of biphasic bioceramic materials with different granulation sizes and their influence on bone repair and inflammation in rat calvaria. Sci Rep. 2021 Feb 24;11(1):4484.Pubmed PMID: 33627770. 